WCOM (World Class Operations Management) 
Carlo Baroncelli · Noela Ballerio Editors

\section{WCOM (World Class Operations Management)}

Why You Need More Than Lean

第 Springer 


\section{Editors}

Carlo Baroncelli
Efeso Consulting SA
Paris
France

\author{
Noela Ballerio \\ Efeso Consulting SA \\ Milan \\ Italy
}

ISBN 978-3-319-30104-4

ISBN 978-3-319-30105-1 (eBook)

DOI 10.1007/978-3-319-30105-1

Library of Congress Control Number: 2016933466

(C) Springer International Publishing Switzerland 2016

This work is subject to copyright. All rights are reserved by the Publisher, whether the whole or part of the material is concerned, specifically the rights of translation, reprinting, reuse of illustrations, recitation, broadcasting, reproduction on microfilms or in any other physical way, and transmission or information storage and retrieval, electronic adaptation, computer software, or by similar or dissimilar methodology now known or hereafter developed.

The use of general descriptive names, registered names, trademarks, service marks, etc. in this publication does not imply, even in the absence of a specific statement, that such names are exempt from the relevant protective laws and regulations and therefore free for general use.

The publisher, the authors and the editors are safe to assume that the advice and information in this book are believed to be true and accurate at the date of publication. Neither the publisher nor the authors or the editors give a warranty, express or implied, with respect to the material contained herein or for any errors or omissions that may have been made.

Printed on acid-free paper

This Springer imprint is published by Springer Nature

The registered company is Springer International Publishing AG Switzerland 


\section{Foreword}

\section{Why Do You Need More Than "Lean"}

The title of the book represents the most frightening and dreadful question all authors of "Lean books" have ever found themselves confronted with. At the sunset of a crisp, windy, rainy day you are there, waiting and feeling rather cold in your best suit, your sweaty palms on your manuscript. As soon as the door opens, you can feel your heart beating as if it were in your mouth, hoping for a piece of advice or getting ready to receive some sort of criticism, but not expecting that question. You stand up to shake hands and you feel as if you were emptied, dizzy like a climber, shocked as if you were struck by lightning: you have never thought about that question before.

Both of us are academicians with twenty-or-so years of experience in teaching undergraduate, graduate, MBA, and Ph.D. students. At the same time, we like advising companies, firms, and businesses in the area of Operations and Supply Chain Management. Over the last couple of years, we have read and revised several books: some of them just for the sake of keeping updated about what's going on in our field; some others because they were written by colleagues, or to get some inspiration for our own textbook.

Never before have we spotted a book providing an angle so remarkably different from the ones we are used to. This is against all the odds and somehow even more surprising, as we share with Mr. Baroncelli the legacy of professor F. Turco (who passed away too early), both a former colleague of ours and one of the founders of EFESO.

The remarks above bring us to the main question of whether there is any need for this book. The answer is yes, definitely. Indeed, this book fills a twofold gap.

On one hand, it states $\mathrm{WCOM}^{\mathrm{TM}}$ as a phenomenon, whose ingredients are techniques, tools, practices, etc., including people and their behaviors, skills, competencies, etc. Actually, WCOM ${ }^{\mathrm{TM}}$ is different from these elements and you have to go through the book to find out what it is. Indeed, we have to consider that the literature on WCM/WCOM ${ }^{\mathrm{TM}}$ is almost sparse and nonexistent. If you google 
"Lean books" you will find 59 million results, while by googling "WCM books" there are much less hits, including the books by R.J. Schonberger. WCOM" produces almost no result, which is, to some extent, surprising as the WCM/WCOM ${ }^{\mathrm{TM}}$ approach has been adopted-besides the five interviewed companies - also by large multinational corporations like Fiat Chrysler Automobiles (FCA), Heineken, Procter and Gamble, Milliken, and many others.

On the other hand - and here we come to the reasons why you need more than "lean"- three major points are to be taken into account.

First, the shift from Breakthrough to Continuous Improvement. The lean transformation is by itself a breakthrough, rather than some sort of Continuous Improvement: WCM/WCOM ${ }^{\mathrm{TM}}$ systems put together two infinite loops. The former contains Kaizen, while the latter contains the Performance Control System (PCS), thus creating a never-ending recurrent system where improvement and variance control waltz together in harmony.

Second, the Human Factor. This book delivers the message that everything in our business is about people. This seminal concept within Autonomous Management is bolded in the third part of this book. People play a major role both on the shop floor and in the boardrooms, they are the key to unlock the potential gain of effectiveness everywhere and, by flipping through the pages, this elementat first almost unnoticed or considered just as one side of the coin - emerges as the main character of the book. This remark triggers some additional insights into the real need to go beyond "Lean." Above all, this book hands over a snap giveaway: "people first, then models." Interestingly, we are used to proceeding in the opposite way, by teaching models first - as if they were better run without people - and then we highlight the human side, the behavioral impact, etc.

Third, the long-term sustainability. Besides the infinite loop, the pillar system allows to orientate the organization to an inter-functional attack to losses. Indeed, this is based on the inherent inter-functional nature of losses, which makes the traditional organizational structures unfit for the need to eradicate the losses permanently. The pillar-based system leads to a learning organization capable to capitalize the knowledge for Continuous Improvement, which provides a long-term sustainability to the Continuous Improvement system almost unknown within traditional lean systems.

This book is arranged into four main sections. In the first section some success cases are told by the leaders of five large multinational groups, each one overviewing the reasons, successes, obstacles, hurdles, and recommendations for those who would be glad to set off for a WCM/WCOM ${ }^{\mathrm{TM}}$ transformation. The second section is devoted to describing the $\mathrm{WCOM}^{\mathrm{TM}}$ model: you will broaden your horizon far wider than the concrete walls of plants and manufacturing facilities to overlook the end-to-end supply chain. The third section focuses on the human side, dealing with the main principles of leadership and behavior. Finally, the fourth section provides an overview of the main contents connected to each pillar of a value chain. 
In conclusion, this book could be a good read for whoever-managers, directors, students - is willing to get more insight into the WCM/WCOM ${ }^{\mathrm{TM}}$ approach, and into what you can find beyond Lean.

Milan, Italy

Roberto Cigolini

Andrea Sianesi 


\section{Preface}

Saint-Gobain since several years has launched a program of World Class Operations Management, which is the application of Continuous Improvement principles to our industrial organization.

As all large companies, Saint-Gobain has to adapt itself to the new world created by globalization.

Consider the long heritage that Saint-Gobain has: it was established in France in 1665, 350 years ago, as Manufacture royale de glaces de miroirs, by Louis XIV. In 1684, Saint-Gobain won the order to create the mirrors that still adorn the Hall of Mirrors in the Royal Palace of Versailles, in the South of Paris. Since then innovation has been the core business and the group, in the different historical phases of its life, has always been leveraging to reinvent and adapt the business model to be at the cutting edge.

The globalization process we have gone through the last 15 years has meant mainly three challenges:

- a wider strategic field, leading to an increasing size of the Company, offering more opportunities for development;

- consequently more complexity in the Organization;

- more competition as well.

To take these three challenges, $\mathrm{WCOM}^{\mathrm{TM}}$ appeared as the most appropriate approach, because

- it creates results,

- it builds a common industrial culture, ensuring a factor of cohesion between persons working for the same company, but in different businesses, countries,

- it develops, through the common culture, the strategic flexibility and reactivity of the company,

- and most important, it empowers the people at the shop floor level and develops their autonomy to adapt and improve permanently the organization. 
In the meantime the art of management has changed. It is not anymore the time when the managers tried to instill their thoughts in the operators pretending they execute. It is more the moment to create, in all decentralized organizations, the best conditions for success. The need for speed and for simple pragmatic solutions to operational problems makes it mandatory to empower the shop floor and make it proactive and autonomous (in problem solving).

In our world, the large Company cannot be managed by a few persons: problems have to be dealt and fixed where they happen, through a large number of empowered employees.

Of course, strategy imports, investments import, innovation imports, but the motivation and the knowledge of all the people is key. And what better way to motivate than to give more responsibilities, more influence on their work and performance, to all the operators?

We consider that, together with innovation and expansion to new markets, WCOM represents the third pillar of our growth journey. We are now extending the approach to the whole value chain, because we consider that, beyond the results already achieved, more is yet to come.

Jean Pierre Floris

Deputy CEO in charge of the Packaging Sector and oversight of the Innovative Materials Sector

of Saint-Gobain

Paris, France 


\section{Acknowledgments}

Besides the authors and contributors to this book, we thank for their precious advice Fjodor Ardizzoia (YellowHub), Giovanni Brembilla (Tenaris), Jasper Boers (Bel Group), Wiebe de Vries (EFESO), Steve Ellam (Carlsberg), Stefano Erba (EFESO), Daniela Gementi (EFESO), Bas Koetsier (EFESO), Günter Kröhn (Lenzing), Giorgio Levati (EFESO), Ross D. Lichtenberg (YellowHub), Filippo Mantegazza (EFESO), Emanuela Nizzolini (EFESO), Jennifer Proctor (APICS), Natasha Puim (Kotter International), Kenneth Snyder (SHINGO Institute), Luca Stoppino (EFESO), Lucas van Engelen (EFESO), Jean Veillon (EFESO), and Jon Woolven (IGT Institute). 


\section{Contents}

\section{Part I Cases and Best Practices}

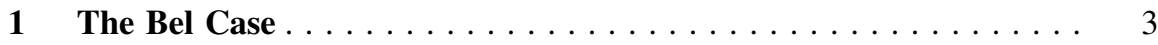

Hubert Mayet

2 The Bemis Case ....................... 9

Thomaz P. Gruber

$3 \quad$ L'Oréal Case . . . . . . . . . . . . . . . . . . . . . . . . . . . . . . . . . 19

Eric Wolff

4 The Saint-Gobain Case. . . . . . . . . . . . . . . . . . . . . . . . . 29

Yannick Courtial

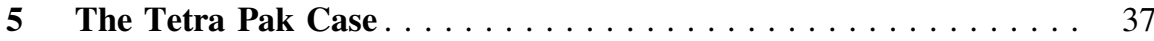

Giovanni de Filippo

\section{Part II The WCOMTM Model}

6 Intro to WCOM'm, Why and What: The Loss Concept . . . . . . . . 49 Carlo Baroncelli

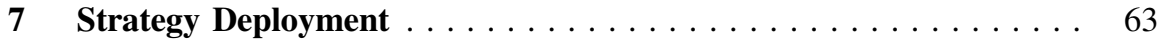

Giorgio Merli and Gaia Zampaglione

8 The Three Phases of WCOMTM $\ldots \ldots \ldots \ldots \ldots \ldots$ Carlo Baroncelli

9 The WCOM'M Organisation: Teamwork, Performance Control, Pillars and Driving System . . . . . . . . . . . . . . . . . . 89 Carlo Baroncelli

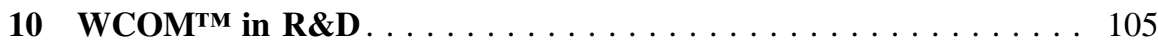
Mario Galassini 


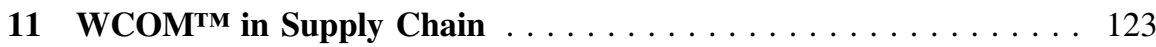
Clive Geldard

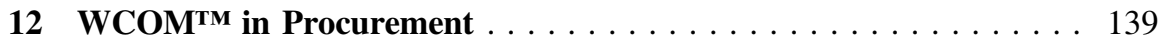
Andrea Montermini

13 WCOMтм Business Process Excellence . . . . . . . . . . . . . . . . . . . 147 Francesco Lecis

14 Implementation . . . . . . . . . . . . . . . . . . . . . 157 Carlo Baroncelli

15 History of TPM and JIPM: The TPM Awards From the Japan Institute of Plant Maintenance (JIPM) . . . . . . . . . . . . . . . . . . 169 Tsutomu Nakamura

\section{Part III The Human Side}

16 The Human Dynamics in WCOM'M . . . . . . . . . . . . . . 183 Rajinder Singh

17 Change Management and Leadership . . . . . . . . . . . . . . . 185 Mark Goodwin

18 Performance Behavior . . . . . . . . . . . . . . . . . . . . . . . . . 197 Neil Webers

19 Shingo Model. . . . . . . . . . . . . . . . . . . . . . . . 217 Mark Baker

20 TWI (Training Within Industry). Rajinder Singh and Noela Ballerio

\section{Part IV Conclusion}

21 Key Patterns for a Common Approach . . . . . . . . . . . . . . . . . . 247 Noela Ballerio and Carlo Baroncelli

Annex: The Value Chain Pillars in Brief . . . . . . . . . . . . . . . . . 259 


\section{Editors and Contributors}

\section{About the Editors}

Carlo Baroncelli is Co-founder of EFESO with more than 35 years' experience in Operations Strategy and World Class Operation Management, leading programs for multinational companies, from Product Development to Supply Chain domain. His most relevant experiences fall into the field of capital intensive industries, in many industrial sectors such as paper, steel, packaging, mechanical, automotive, and pharma.

He has been a member of the Board of Directors since 2007 and was responsible for the Knowledge Development of EFESO Group in the past.

He holds a Master's degree in Industrial Engineering from Politecnico di Milano, postgraduate courses at MIT in USA and at JIPM in Japan.

He has been academically involved in multiple roles, is responsible for the Manufacturing and Logistics' Area at the School of Management at Genova University, and is lecturer at ISTUD and MIP (Master of the Politecnico di Milano) and at Bergamo University.

$\mathrm{He}$ is former Vice-President of the Italian Chapter of the Society of Logistics Engineers.

Noela Ballerio is Senior Knowledge Manager at EFESO, with 15 years' experience in knowledge \& linguistics management and training.

She obtained a Law Degree specialising in Juridical Anthropology \& Ethnology at Milan University.

During university she worked as a swimming teacher for children and disabled people.

After university she practiced as a lawyer and cultivated her passion for social sciences by attending a drama academy in Milan as well as seminars in drama therapy and conflict management.

She joined EFESO in 2001 covering the roles of Translation Manager, Knowledge \& Communication Manager and Knowledge Senior Manager. 
She is actually working in the EFESO Toolkit Team for knowledge development, especially in the Change Management area, as well as in training and people development.

She writes and draws children tales, translates books, makes readings.

\section{Contributors}

Mark Baker is pursuing a career in operations leadership and quality management spanning 30 years across 30 countries. He began his career as a mechanical engineer for Honda Motor Company, engaged in the development of production system technologies.After earning his MBA he spent the next two decades with Saint-Gobain, one of the largest industrial corporations in the world, engaged in a variety of operational and quality leadership roles. As former Executive Director of the Shingo Institute, Mark continues to be actively engaged in helping executives around the world to deliver world class performance in a wide variety of industries, including automotive, steel, high performance materials, financial services, and healthcare.

Roberto Cigolini is professor of "Supply Chain Management" and "Production Management" at the Department of Management Economics and Industrial Engineering of Politecnico di Milano. His main interests are primarily related to business planning and control, indirect procurement, contracts negotiation, and real estate management.

He graduated cum laude in Management Engineering from Politecnico di Milano. He is director of the Global Executive Master in Operations and Supply chain management (GEMOS) at MIP-Politecnico di Milano Graduate School of Business, where he was co-Director of the MBA program. He is also co-director of the executive course in Real Estate Management. He is a member of the teaching body of the Ph.D. in Management Engineering at Politecnico di Milano and founding member of the Technical Committee on Semiconductor Factory Automation (IEEE Robotics and Automation Society).

Yannick Courtial is the Operational Excellence Vice-President at Saint-Gobain. $\mathrm{He}$ is graduated in Materials Science and Engineering from INSA Lyon.

After 15 years at Danone, and 12 years at Saint-Gobain, he is Operational Excellence Vice-President (World Class Manufacturing/World Class Supply Chain) at Saint-Gobain.

Giovanni de Filippo is former Vice-President, Capital Equipment Tetra Pak.

He holds a degree in Electrical Engineering from Politecnico di Milano. After graduating, he joined the Pirelli Tyre Sector in Milan in 1976, as Technical Manager responsible for the Engineering and the Maintenance Services of the Pirelli factory in Patras, he then becams Plant Manager. Then he was appointed Director of the Industrial Efficiency Department of the Tyre Sector of Pirelli Coordinamento Pneumatici Spa. He then moved to Allied Signal Braking Systems 
Europe, as Lean Manufacturing Manager Europe, where his main responsibility was to study and implement in European factories the most modern "Lean Manufacturing" methodologies, particularly TPM (Total Productive Maintenance).

He was appointed Director of the Aftermarket Operations organization, a new European Business Unit that he was responsible to create, organize, and staff; he maintained this assignment also through and after the acquisition of Allied Signal Braking Systems by Robert Bosch GmbH, in April 1996. He joined Tetra Pak in Modena in December 1998 as Director Converting worldwide. After that, he held several managerial positions until 2006, when he was appointed as Vice-President, Supply Chain Capital Equipment.

Giovanni retired from the company at the end of 2014.

Mario Galassini has an M.Sc. in Management Engineering from Politecnico di Milano. He joined EFESO in 1993 and has more than 20 years' experience in Engineering, Product Development, WCOM, and Supply Chain projects.

He has developed the most relevant experiences the field of Product and Process Development. Leader of Innovation Knowledge Group.

He has long experience in strategic NPD projects for multinational companiesNew products, Greenfields, new processes, Industrialization and product range optimization, and experience in Service design and reengineering in various fields.

He has also developed the World Class Operation Management Practice for multinational companies and medium sized factories, from Product Development to Supply Chain domain.

Mario assists clients of many industrial sectors, from Automotive to Food, Personal Care, Mechanical and Engineering and Public Administration.

He has supported the development of EFESO Knowledge Management system, collecting many experiences of the group's international experts into the WCOM Toolkit.

Clive Geldard is Group Vice-President responsible for the global Retail and Supply Chain practice of international consultancy EFESO. He has 25+ years' experience in end-to-end supply chain, logistics and distribution channel management, both in Operations and as a Management Consultant.

He has worked in complex multi-channel B2B and B2C businesses in the UK, Europe, and developing markets in the Middle East and Africa. Initially working in the Automotive Aftermarket and Distribution sector, he moved into Retail and Consumer Products working with companies such as ECOLAB, Unilever, L'Oréal, Imperial Tobacco, Tetra Pak, and Apple and retailers such as Wal-Mart, Co-op, Pick n Pay, Primark and Jerónimo Martins. Most of his career has been spent managing and implementing change, working with clients to help them build the capability to support strategic supply chain transformations and continuous improvement.

Clive is co-author of research papers "Supply Chain in the Boardroom-Closing the Implementation Gap" and "Successful Supply Chain Strategies for Emerging 
Markets." He has special interests in Complexity Management, Supply Chain Design, and Route to Market.

Mark Goodwin brings an unusually broad range of experience to a leadership role in Efeso, having had five different careers: in diplomacy, consulting, manufacturing, tropical farming, and psychotherapy.

Following his Master's in Nuclear Physics at Oxford he joined the Diplomatic service (UK Government) in the South Pacific, helping the Gilbert Islands attain independence as one of the last Colonial Commissioners.

He learned shop-floor consulting methods with Alexander Proudfoot in Europe and rose to become the Director General in 1983.

He was the founder and Chief Executive of Booker Tate, the world's largest tropical farmer between 1983 and 1990.

He was the founder and Chief Executive of Booker Tate, the world's largest tropical farmer between 1983 and 1990.

He was the Chief of Staff for Carnaud Metalbox in Paris, Europe's largest metal packaging company. This is where he hired EFESO to help him with a new factory culture.

$\mathrm{He}$ is a trained psychotherapist, being a member of the Institute of Group Analysis and the UK Council of Psychotherapists.

His global experience spans a large range of industries and includes experience in 166 countries.

Thomaz P. Gruber is Senior Vice-President, Supply Chain and Operations at Bemis NA (USA).

He reports to President of BNA and is a member of the executive leadership team. He is responsible for implementing the vision of the new Organization and for delivering the Safety, Quality, Service, and Cost metrics. He is functionally responsible for Manufacturing (25 plants, 6000 employees), Engineering, WCOM, Quality, Graphics and Supply Chain and Logistics.

His previous leadership experiences are in Toga Group in Brasil, in US, and in Bemis, Europe.

Thomaz P. Gruber has a Master's in Business Administration-Marketing and Finance Cornell University-S.C. Johnson School of Management and a Bachelor's Degree, Chemical Engineering at Mackenzie University (Sao Paulo, Brasil).

Francesco Lecis is a mechanical engineer.

He began his career in Tenaris-Dalmine (worldwide pipe steel company) covering different roles in production and manufacturing.

He joined EFESO in 2002. In EFESO he developed his expertise in operational excellence, mainly in lean transformations and supply chain reengineering for the mechanical assembly sector.

From 2012 he is Vice-President and drives worldwide projects of "Lean production" and "World Class Operations Management." 
Francesco is now worldwide responsible for all business process practices and is currently leading large Lean implementation programs for multinationals.

Francesco is a Six Sigma Master Black Belt and has obtained the licence of "workload analyst."

Hubert Mayet is General Manager of the Bel Group in charge of Manufacturing and Technical Direction, and a member of the Executive Committee.

Since he joined the Bel Group in 1979 he has held different positions in R\&D, Production as Plant Manager (Minibabybel) and Industrial Director for Processed Cheese Activity.

Hubert Mayet is a graduate from Agro Paris Tech (ENSIA).

Giorgio Merli is Professor in Milan Bicocca University, Pisa Sant'Anna Scuola Superiore, Bergamo Universities Strategy Master, and the author of more than thirty books published in several languages. He is former Country Leader of IBM Management Consulting Services (2002-2009), President and CEO of PriceWaterhouseCoopersConsulting Italy (1999-2001) and EMEA Leader for the Operations Strategy Service line of both, Senior Advisor to KPMG (2010-2011), Senior Partner of Galgano Group (1978-1998). In 2008-2009 he was also President of the Consulting Area of CONFINDUSTRIA (Italian Industrials Association) and member of Corporate Sustainable Development Panel of EDF (2009-2011). He is currently Senior VP at EFESO. A graduate engineer with a Master's degree in Manufacturing Management, Merli started his career at Philips, where he became Manufacturing Director. Consultant since 1978, he has carried out several reorganization projects in Italian and multinational companies. He has been particularly involved in the implementation of advanced Management and Planning Processes, Business Excellence Model and Lean Production/Lean Organization (WCOM). Presently he is studying, teaching, and consulting on Innovation matters and Business Model Evolutions.

Andrea Montermini has been working as a management consultant since 1998, having acquired core competences in business planning, transactions, cost management, supply chain, sourcing, organization.

He has mainly been assisting companies from various industrial sectors, such as Aerospace and Defence, automotive, transportation, electromechanical, and electronics.

Today as Vice-President of EFESO Consulting, he leads the Group activities in three practices, notably the Aerospace and Defence industry, the Strategic Cost Management practice and the Litigation Support business unit.

Before joining EFESO he was Director and co-founder of Blupeter in Italy, and formerly senior manager at Solving International and member of the Group's International Technical Committee.

He graduated in Management Engineering at Politecnico di Milano. He was born in 1972. 
Tsumotu Nakamura after attending the School of Business Administration in Senshu University and graduating in 1989, joined the Japan Institute of Plant Maintenance (JIPM).

He has been covering different prestigious positions before becoming General Manager. He is authors of publications as Total Productive Maintenance, "Encyclopaedia of Statistics in Quality and Reliability" John Wiley \& Sons Inc., 2008 February, "The source of the competitive power in the European company" Nikkei Monodukuri Magazine, 2007 January and "The Japan style manufacturing in the European manufacturing" Nikkei Monodukuri Magazine, 2005 December.

Andrea Sianesi is Full Professor at the Department of Management Economics and Industrial Engineering, and Dean of MIP, the Graduate School of Business of Politecnico di Milano.

He has extensive teaching experience in several Italian universities. He has also been visiting professor and researcher in foreign universities. He is a member of the Management Committee of ASFOR (Italian Association of Management Development) and of ANIMP (Italian Association of Industrial Plant Engineering). He has about a hundred articles published in renowned international journals and conferences.

Rajinder Singh is Vice-President and Managing Director of EFESO, India. He has over thirty years of hands-on experience in designing and implementing manufacturing systems based on Lean principles. He is a Professional Trainer, Mentor and Coach for Operational Transformation of Manufacturing and Service Organizations. His rich experience with multinationals such as Ford and Delphi, along with his passion for Lean thinking has made him one of the leading Lean consultants in India. As a consultant he has executed several high-impact projects with companies located in India, Dubai, Egypt, Singapore, Germany, China, and Mauritius.

Neil Webers is Vice-President and Managing Director of EFESO The Netherlands, and member of the group domain management team. As Performance Behavior expert he has published numerous articles and has written several books on his expertise: the connection between the behavior of people and the performance of an organization. He studied business and worked in retail operations before founding his own company on behavioral performance improvement, which was acquired by EFESO in 2013.

In his Performance Behavior book (US version published 2012), Neil reveals the secret of improving performance driven by a sustainable behavioral organizational change. He discloses how to make behavior measurable and explains different behavioral profiles, the steering and accountability structure and action indicatorscrucial factors necessary in facilitating the measurement and steering of behavior. This unique approach sets the new standard in creating ownership, discipline, and responsibility to continuously improve a company's results. 
Eric Wolff has a background in Food Industry and Biotechnology and a Ph.D. in Chemical Engineering. From a Research and Development career starting point, he moved to L'Oréal in 1992 and has covered different positions in Process development, Manufacturing, and Quality in Europe and North America. He was Quality Manager in the L'Oréal plant in Belgium, Quality Manager for the North America global Zone (covering 9 factories and a global lab) in the US, Plant Manager in Montréal (QC) - Canada, then Worldwide Corporate Manufacturing Manager and since 2011 he is Worldwide Corporate Quality and Manufacturing Director for the entire L'Oréal Group, directly reporting to WW Group COO.

Gaia Zampaglione has worked in EFESO as Consultant and Knowledge Expert from 2010 to 2015. She supported organizations and leaders to change for better their organizations. Her main areas of expertise are Operational Excellence and Lean implementation in the end to end value chain, in parallel with the capability to sustain the change with knowledge management activities and platforms. She is an Engineer from the Politecnico di Milano. Prior to working in EFESO, she has been a consultant in Kaizen Institute for two years. 


\section{Introduction}

My first-ever encounter with what is today known as Operational Excellence occurred in November 1984 when, after some years working in the industrial office of a large electrical appliances company, I was fortunate enough to participate in a training program that entailed a long study abroad organized by the Japan Institute of Plant Maintenance. Back then, Japan was at the forefront in production systems and had near stunning conditions as compared to our industrial world. The performance and cultural gap was huge. We as visitors, a mixed group of delegates from universities and international industrial companies, were unable to even come up with the right "questions" to ask: we asked about their planning and control and IT systems, their automation implementation, their organizational structures, and they weren't able to comprehend our questions. They answered by saying their success was based on principles, philosophy, participation and involvement: it was as if we were speaking two different languages.

I finally began to understand a little bit more the following year when I attended lectures held by Richard Schonberger in the United States. Over a two-month period in summer 1985, alongside Filippo Mantegazza ${ }^{1}$, we paid a series of visits to Japanese trans-plants and innovative companies. The "pull" system was explained to us by a very kind assembly line leader in Oregon at a brand new Hewlett Packard printing plant. Up until the previous summer, this woman had been driving tractors (she was a farmer that made the switch after the birth of the ICT industry on the west coast) and she did not have a predisposition to MRP or Wilson's formula for economic order quantity. With that being said, and without any sort of predetermined method, she adopted with ease the methods that, after Womak and Jones' research at MIT, would become known as "lean".

Since then, three decades have gone by, and the entire global industry has taken steps forward, transitioning from consolidated models based on Taylor and Ford's offerings to modern production methods.

\footnotetext{
${ }^{1}$ Filippo Mantegazza is the Chief Executive Officer of EFESO Consulting
} 
Over the years, I have had the opportunity to collaborate with one of the most creative and innovative teams out there ${ }^{2}$, one of the first in the western world to gradually introduce such auspicious methodologies and approaches.

From those first rudimentary attempts at introducing Just In Time production as well as Total Quality, supported by the Theory of Constraints, to the adoption of Total Productive Maintenance, to World Class Manufacturing and the most recent approaches based on Change Management, Performance Behavior and the Principles of the Shingo Institute, these 30 years have gone by in the snap of a finger, highly concentrated on demanding challenges, helping large groups to "change" in order to survive and prosper.

World Class Operations Management (WCOM ${ }^{\mathrm{TM}}$ ) is the combination of hundreds of successful cases in various continents, spanning all latitudes and various cultural conditions. In addition to harmoniously integrating Lean, TPM and Six Sigma, all of which explain the "what", the WCOM" model adds value, compared to these previous approaches, by providing a robust explanation of the "why" and "how," which in this day and age are the most important questions to ask.

What separates this book from a management textbook is that it does not focus solely on the recipe for success, but tells real stories, with difficulties, obstacles and possible countermeasures.

Considering that we wanted this book to offer the best in the business regarding Operational Excellence, we tied together the experiences of large industrial groups as well as the most innovative and interesting approaches. Together, these elements created the foundation for the WCOM ${ }^{\mathrm{TM}}$ experience.

A special thanks goes out to all the contributors, whose experience played a big role in this book.

I believe that, with all these experiences meshed together, they combine for hundreds of years of work experience, the turnaround of various international groups and the switch to OPEX in thousands of different organizations.

Carlo Baroncelli

\footnotetext{
${ }^{2}$ The EFESO Team
} 